Article

\title{
Reducing the Content of Metal Ions from Mine Water by Using Converter Sludge
}

\author{
Lucia Rozumová ${ }^{1,2, *}$ (1) and Jana Prehradná ${ }^{1}$

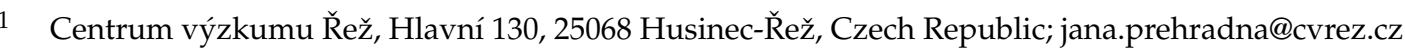 \\ 2 Centrum nanotechnologií, VŠB-TU Ostrava, 17. listopadu 15, 70833 Ostrava, Czech Republic \\ * Correspondence: lucia.rozumova@cvrez.cz; Tel.: +420-601-291-879
}

Received: 9 November 2017; Accepted: 3 January 2018; Published: 4 January 2018

\begin{abstract}
The aim of this paper was to study of utilization of converter sludge waste as a sorbent. The sorbent was utilized to reduce the content of manganese, cobalt, and nickel ions from mine water. Sorbent utilized in this work was obtained from the metallurgical industry from a process of gas treatment in an oxygen converter. Converter sludge was characterized by X-ray diffraction, Scanning Electron Microscope, X-ray fluorescence spectroscopy, Specific Surface Area and Particle Size. Sorption experiments were conducted in a batch mode by using the real mine water. The impact of $\mathrm{pH}$ and contact time on the pollutant removal efficiency was observed. The sorption kinetics were evaluated with pseudo-first and pseudo-second order kinetic models. For the tested materials, the highest level of mine water purification was achieved; thus, the mine water could be discharged into the watercourse. The results of this study indicate that the application of metallurgical waste as a sorbent is highly effective for the treatment of multicomponent mine water.
\end{abstract}

Keywords: converter sludge; mine water; sorption

\section{Introduction}

Metallurgy is a major industrial sector as well as one of the largest environmental polluters. The Czech Republic has a high proportion of metallurgical production in the metallurgy field, resulting in a prominent level of pollution and a large ecological impact. The production of iron and steel in the Czech Republic generated 878,675 tons of wastes in 2014, of which the proportion of waste sludge was counted as 26.633 tons [1].

In the environmental hierarchy, metallurgy is among the major producers of massive quantities of waste in addition to one of the leading producers of air pollution, representing a wide range of substances with different consistencies, and different physical, chemical, and mineralogical compositions [2]. Currently, the metallurgical process produces a large amount of solid waste, such as slag, dust, sludge, and sewage. A majority of this waste contains a significant amount of iron and constitutes a source of potentially hazardous metals, such as zinc, lead, cadmium, and arsenic. According to the content of hazardous pollutants, these wastes are further treated. This waste is inefficiently redesigned, causing considerable economic and environmental losses. With the development of novel science, technology, and environmental protection, the trend of improving production technologies and minimizing waste production and waste storage in landfills is increasing [3].

Recently, significant attention is focused on the usage of industrial waste materials, since this waste is an unused resource and in many cases can cause serious liquidation problems. Waste from iron and steel production is an important secondary raw material because of its high content of iron [4]. Currently, efforts to reuse such waste in a briquette production process as a part of the batch for iron production has been undertaken. A fine converter sludge (CS) is mixed with a converter dust, and their mixture is used in the construction industry for cement production $[5,6]$. 
Awareness of the environmental impact and concern for the environment has been increased in recent decades. Water management strategies of the international mining industry are used to minimize the environmental impact of mining operations, and now they are the heart of the mine development. In order to protect the environment, the quality of water leaving mine sites into downstream waters must be evaluated. Mining companies develop water management plans to minimize the potential of water contamination and to prevent the release of polluted water into the environment [7].

A number of new technologies for the removal of heavy metals from wastewater has been developed. The predominant applied methods are coagulation, flocculation, precipitation, electrochemical processes, ion exchange, extraction, etc.; using a suitable sorbent is another favorable way of removing pollutants from wastewater. Price, availability, adsorption capacity, and strong affinity to pollutants are limiting factors for sorbent application in wastewater treatment; hence, new materials to be used as sorbents are constantly being evaluated [6].

Adsorption has become a popular method for the removal of heavy metals from mine water and wastewater. Natural materials, waste, and residue products from industrial or agricultural activities have excellent potential as economic adsorbents for heavy metals removal from aqueous solutions. The reduction of acidity and removal of metal ions from coal mining effluents using chitosan microspheres [8], zeolites [9], blast furnace slag [10], fly ash zeolite [11], and phosphatized dolomite [12] have been studied.

Investigating the competitive adsorption of certain metal ions on CS sorbent is rather complicated. The competitive effect of heavy metal ions on a CS sample has never been studied.

In general, the methods of mine water purification can be divided into active and passive approaches. Active methods use chemical reagents and energy. The advantage of active methods is the high efficiency of the process. The disadvantage is their financial difficulty, high consumption of chemicals, costs of operation, and maintenance of the treatment plant, as well as the costs associated with the sludge disposal [13]. The passive method works on the principle of using naturally available energy sources in systems that require minimal maintenance; this method has lower costs, although it also has low efficiency and is time consuming. Recently, there have also been combinations of active and passive methods, mainly arising from the pursuit of ecological approaches and cost reduction. However, conventional methods such as lime-based chemical precipitation, ion exchange, and other processes have a number of shortcomings; extensive land utilization, the production of large secondary solid waste, and high capital and operating costs are among them.

The purpose of using waste materials as a sorbent brings two advantages regarding environmental pollution. The first advantage is the potential reduction of the volume of solid waste materials. The second is in the use of the waste as sorbents, which can effectively reduce wastewater toxicity at reasonably low costs $[14,15]$.

This work is focused on the study of the removal of manganese, cobalt, and nickel ions contained in a mine water sample using waste materials generated in an oxygen converter of a flue gas treatment plant. The main objective of the work is to reduce the monitored parameters below the limit values for the discharge of mine water into the environment.

\section{Materials and Methods}

\subsection{Materials}

In a steel converter, oxygen is blown off by molten, carbon-rich raw iron, which reduces the carbon content of the alloy and converts it into the steel. The CS, resulting from the wet scrubbing of the gas formed, consists predominantly of iron oxides and a portion of calcium. Hematite and magnetite can be detected in CS [16]. The CS sample used in this study was obtained from a wet purification process of combustion products of the steel production from a plant located in the Czech Republic. The CS sample consisted of a dry powder without pre-treatment. The CS sample was separated into fractions and subjugated to homogenization and sieve analysis before the primary analysis and 
sorption experiment. The particle size of the material used in the experiment was in the range of 100-200 $\mu \mathrm{m}$. Subsequently, an analysis of the aqueous leachate of the CS sample was performed according to the standard EN 12457-4:2002 [17]. For further experimental work, the materials were prepared from the original samples, in which the soluble components were removed by the process according to EN 12457-4:2002 [17], where the methods of removing are defined. The chemical and phase composition of the CS sample were determined. Specific surface and pore sizes were also measured. The prepared aqueous leachate was analyzed and inorganic pollutants, fluorides, chlorides, sulphates, dissolved organic carbon, and the phenolic index were determined. According to EU (European Union) standard 200/532/EC [18]., which details a list of hazardous waste, tested waste belongs to the category of waste from iron and steel industry. In the European Waste List, it is listed as No. 100214-sludge and filter cakes from gas treatment [18]. Thus, CS was pre-treated by washing with water.

A mine water (MW) sample for laboratory experiments was obtained from a brown coal mine area, which is located in the Czech Republic. This sample of MW was collected from the surface of a mining pit area, where the water is mixed. The sample was filtered from suspended solid particles and coarse impurities by using a membrane filter with a pore size of $0.45 \mu \mathrm{m}$ before the analyses and sorption experiment. The filtered MW sample was used to measure the concentrations of selected indicators monitored in the MW treatment plant.

\subsection{Methods of Material Characterization}

\subsubsection{XRF Analysis}

An ARL 9400 XP X-ray fluorescence (XRF) spectrometer (Thermo ARL, Pardubice, Czech Republic) was used to determine the chemical composition of the material. CS sorbent was characterized in its original state (powder). For the XRF analysis, the CS sample was taken and mixed with a wax. A pulverizing mill was utilized to obtain a homogeneous dispersion and uniform particle size of the resultant mixture (sorbent and wax). Pressed pellets for XRF analysis were prepared from the mixture by applying a hydraulic pressure of 10 metric tons to compress the sample.

The XRF spectrometer provides a fully automatic sequence for qualitative and quantitative element analysis. It is equipped with an Rh tube, $4 \mathrm{~kW}$ generator, crystals (TIAP_Thallium Acid Phthalate, Ge 111, LiF 200, LiF 220), and two detectors: proportional and scintillation. Standard-less analysis was made using Uniquant 4 software (Thermo ARL, Pardubice, Czech Republic).

\subsubsection{XRD Analysis}

The CS samples were characterized by X-ray diffraction (XRD) analysis in a Bruker D2 Phaser diffractometer (Brucker, Vienna, Austria).in the Bragg-Brentano geometry. The XRD $\theta-2 \theta$ scans were acquired in an angle range of $10-100^{\circ} 2 \theta$ with a step size of $0.05^{\circ} 2 \theta$. Cobalt X-ray lamp with the radiation of $\mathrm{Cu}-\mathrm{K} \alpha 1(\lambda=0.1789 \mathrm{~nm})$ and output power of $300 \mathrm{~W}$ was used for diffraction. Each scan was registered over $5 \mathrm{~h}$. The diffraction patterns were matched with the PDF reference database and refined by Rietveld analysis.

\subsubsection{SEM}

Scanning electron microscopy (SEM) LYRA 3 (TESCAN, Brno, Czech Republic) was utilized to investigate the structure of CS and to perform a detailed analysis of particles morphology and their chemical composition. SEM micrographs were taken at different magnifications. The SEM was equipped with an energy dispersive (EDX) X-ray spectrometer (TESCAN, Brno, Czech Republic), which was used for quantitative elemental analysis and for recording elementary maps of adsorbed metals. Secondary electron (SE) (TESCAN, Brno, Czech Republic) and backscattered electron (BSE) detectors (TESCAN, Brno, Czech Republic) were used for the surface analysis.2.2.4. Surface Area and Pore Size Distribution 
Surface area and pore size distribution were measured using a QUADRASORB EVO/SI analyzer (Quantachrome, Prague, Czech Republic). The surface area was measured by the BET (BrunauerEmmett-Teller) nitrogen adsorption technique at $-195.8^{\circ} \mathrm{C}$. The CS was outgassed in a vacuum for $72 \mathrm{~h}$ at $40{ }^{\circ} \mathrm{C}$ before analysis. The pore size distribution was measured by analyzing the desorption branches of the isotherm using the Barrett-Joyner-Halenda $(\mathrm{BJH})$ method. The measured data were evaluated by QuadraWin software (Quantachrome, Prague, Czech Republic).

\subsubsection{Concentration of Metals}

The aqueous extracts were prepared according to the standard CSN EN 12457-44 [17], and analyzed by reference methods for the water analysis. A WiseShake (WISD) horizontal circular motion shaker (Verkon, Prague, Czech Republic) was used to mix the samples. A vacuum filtration device with membrane filters with a pore size of $0.45 \mu \mathrm{m}$ was used for the filtration of the aqueous extract. Determination of the metal ions concentration in the water solutions was performed by atomic absorption spectrometry with a flame atomization FA-AAS SOLAAR M6 (Analyte Jena AG, Jena, Germany).

\subsection{Methodology of the Experiment}

A sorption experiment was carried out on the CS sample by using an MW sample as an adsorbate. The CS sample after the sorption experiment was subjected to morphology studies using SEM to obtain information on the distribution of the observed elements. Simultaneously, a desorption experiment was conducted to show the strength of the adsorbent-adsorbent interaction. The experimental results were evaluated using adsorption efficiency, distribution coefficient, appropriate kinetic models, and adsorption isotherms.

Moreover, a single metal ions experiment was carried out using $100 \mathrm{~mL}$ distilled water and $0.25 \mathrm{~g}$ CS sorbent. The real experiment was performed using $100 \mathrm{~mL}$ real MW and $0.25 \mathrm{~g}$ CS sorbent. The MW sample was composed of raw water without removing the undissolved substances before the sorption experiment. The prepared suspension was shaken using a horizontal shaker at $10 \mathrm{RPM}$ at laboratory temperature. After shaking time, CS sorbent was filtered through a $0.45-\mu \mathrm{m}$ membrane filter (MILLIPORE MF) (Merck, Prague, Czech Republic). The concentration of Mn(II), Co (II), and Ni(II) ions in the filtrate was analyzed using FA-AAS (Analyte Jena AG, Jena, Germany).

The desorption experiment was evaluated on the basis of the stability and bond strength of metal ions. The experiment was assessed on the basis of the observed concentration of metal ions leached out into distilled water. The dried solid residues of the CS sorbent after sorption experiments was used for the evaluation. This dried sample was subsequently used for the formation of aqueous leachate in the same ratio-solid and liquid phase, mixing with distilled water. The resulting suspension was shaken for $168 \mathrm{~h}$ at room temperature. Thereafter, the solid phase was separated by filtration, using a $0.45-\mu \mathrm{m}$ membrane filter. The concentration of the monitored ions was determined in the filtrate and the leached portion of adsorbed ions on CS was determined. The leached portion of the ions was measured using FA-AAS. The obtained data were evaluated using the calculated efficiency of the elongated fraction.

\subsection{Evaluation of the Sorption Process}

Evaluation of the sorption process is governed by several important processes which should be considered and can be described by adsorption efficiency, distribution coefficients, and kinetic models.

The adsorption efficiency $(E)$ is the quantity that expresses the amount of adsorbate removed from the aqueous solution calculated from the initial concentration.

The adsorption efficiency is expressed as a percentage in Equation (1):

$$
E=\frac{c_{0}-c_{e}}{c_{0}} \times 100
$$


where $c_{0}$ is the initial concentration of adsorbate $\left(\mathrm{mg} \cdot \mathrm{dm}^{-3}\right)$ and $c_{e}$ is the equilibrium adsorbate concentration $\left(\mathrm{mg} \cdot \mathrm{dm}^{-3}\right)$.

The distribution coefficient $\left(K_{D}\right)$ is a constant that simplifies the relationship between the adsorbent and the adsorbed compound. This parameter is important when the assessed metal interacts and adsorbs solid materials. The values of the distribution coefficients of a number of metal ions are important for understanding the selectivity of a specific metal ion. $K_{D}$ can be considered as the simplest form of isotherm which expresses the linear dependence of the concentration of the adsorbed substance on the concentration of the substance dissolved in the solution. This experimentally determined coefficient reflects the competition of solid particles in the liquid phase with impurities; however, it is not a real competition for impurities of solid particles with water [19]. The distribution coefficient is defined as the ratio of the adsorbate adsorbed by the weight of the solid to the amount of metal in the solution. It can be described by Equation (2):

$$
K_{D}=\frac{c_{s}}{c_{e}}
$$

where $K_{D}$ is the distribution coefficient $\left(\mathrm{dm}^{3} \cdot \mathrm{g}^{-1}\right), c_{s}$ is the equilibrium concentration of the adsorbed substance $\left(\mathrm{mg} \cdot \mathrm{g}^{-1}\right)$, and $c_{e}$ is the equilibrium concentration of the substance in solution $\left(\mathrm{mg} \cdot \mathrm{dm}^{-3}\right)$.

Kinetic studies are important for detecting adsorption mechanisms and controlling rate possibilities, such as mass transfer or chemical reaction processes. Adsorption kinetics are most commonly described by kinetic models of the pseudo-first and pseudo-second order.

The kinetic model of the pseudo-first order, also called the Lagergen model, was firstly used to describe the adsorption at the solid-liquid interface. The basis of this model is the capacity of the solid. Derivation from the Lagergren equation requires that the concentration of the two ions be time-independent and, therefore, the constant should correspond to the linear combination of both concentration values. The Lagergren equation represents the adsorption in the case of diffusion across the liquid phase boundary to a solid sorbent. The constant of the equation varies depending on the particle size and surface film thickness, where the constant is dependent on the concentration of ions in the solution and the process temperature in the case of chemisorption. The particle size does not affect adsorption [20]. The pseudo-first order equation can be expressed by Equation (3):

$$
q_{t}=q_{e}\left(1-e^{-k_{1} t}\right)
$$

where $q_{e}$ is the amount of the adsorbed metal ions in equilibrium and $q_{t}$ is the amount of the adsorbed metal at a specific time $t(\mathrm{~min})$ per unit mass of sorbent in $\mathrm{mg} \cdot \mathrm{g}^{-1} \cdot k_{1}$ is the Lagergren pseudo-first order rate constant $\left(\mathrm{min}^{-1}\right)$, and corresponds to the adsorption time (min). The speed constant $k_{1}$ determines the time factor necessary to achieve the system equilibrium [21].

The kinetic model of the pseudo-second order is based on the assumption of chemisorption as the main mechanism of the process, and is capable of sufficiently predicting the adsorption behavior throughout the process. It is based on the assumption that chemical adsorption may limit the rate of adsorption/desorption. This model is compared to the pseudo-first order model and is considered to be more suitable to represent kinetic data because of the assumption that the chemisorption can be a step limiting the rate of adsorption. Metal ions in the chemisorption are trapped on the surface of the adsorbent and form a chemical bond [22].

The pseudo-second order kinetic model is based on Langmuir's adsorption model on a solid surface, where it is assumed that the adsorption rate is proportional to the concentration of the dissolved substance in the solution and the number of free adsorption sites. Desorption is the release of one substance from another, either from the surface or through the surface. Desorption can occur when an equilibrium situation is altered [23]. The kinetic equation of the pseudo-second order is described by Equation (4):

$$
q_{t}=\frac{q_{e}^{2} k_{2} t}{1+q_{e} k_{2} t}
$$


where $q_{e}$ is the amount of the adsorbate in equilibrium and $q_{t}$ is the amount of the adsorbate at time $t(\mathrm{~min})$ per unit weight of the sorbent $\left(\mathrm{mg} \cdot \mathrm{g}^{-1}\right) \cdot k_{2}$ is the pseudo-second order adsorption velocity constant $\left(\mathrm{g} \cdot \mathrm{mg}^{-1} \cdot \mathrm{min}^{-1}\right)$.

Two known isotherm models (Langmuir and Freundlich) have been applied to describe the experimental data in a single metal ions system with distilled water. The classical non-competitive Langmuir isotherm model for the adsorption of one component is expressed by Equation (5):

$$
q=q_{\max } \times \frac{K_{L} \cdot c_{e}}{1+K_{L} \cdot c_{e}}
$$

where $c_{e}\left(\mathrm{mg} \cdot \mathrm{dm}^{-3}\right)$ is the equilibrium concentration of metal ions, and $q\left(\mathrm{mg} \cdot \mathrm{g}^{-1}\right)$ is the amount of metal ions adsorbed per unit mass of adsorbent. $K_{L}$ and $q_{\max }\left(\mathrm{mg} \cdot \mathrm{g}^{-1}\right)$ are Langmuir constants related to the rate of adsorption and adsorption capacity, respectively.

The Freundlich isotherm is expressed by Equation (6):

$$
q_{e}=K_{F} c_{e}^{1 / n}
$$

where $K_{F}$ and $n$ are Freundlich isotherm constants [6].

\section{Results and Discussion}

\subsection{Characterization of the Converter Sludge and Mine Water}

The original sample of CS was rinsed with distilled water in order to flood out any water-solubilized substances. The aqueous leachate was prepared for the original CS sample and for the rinsed CS sample. Results of the aqueous leachate of both CS samples are summarized in Table 1. The parameters of chloride, sulphate, $\mathrm{Cr}, \mathrm{Fe}, \mathrm{Mg}$, and dissolved organic carbon (DOC) increase, as can be seen from the comparison of the CS samples before and after rinsing. Moreover, $\mathrm{pH}$, fluoride, $\mathrm{Zn}$, and dissolved substances (DS) parameters reduce. The parameters of $\mathrm{Mg}$ and Mo increase, while Ca and Na decrease. By analyzing the liquid phase, it was confirmed that the CS sample does not exceed the maximum permissible concentrations of inorganic pollutants of leachability classes II and III, which are defined in the waste classification of the Council Directive 1999/31/EC [13].

The CS sample was subjected to the chemical analysis of the solid phase. The chemical composition of CS is shown in Table 2. The results show that the CS sample has a high content of $\mathrm{Zn}$ and Cd, thus, it cannot be recycled by conventional recycling methods or used as a raw material in metallurgical units.

The surface morphology analysis of the CS was performed using SEM. SEM images are shown in Figure 1, where significant clusters of particles are evident. Using higher magnification allows us to ascertain that these clusters are formed into small spherical particles with sizes varying in the micrometer scale. Significant clusters might be created due to the free drying of the sludge after the wet cleaning process. CS is characterized by a large proportion of spherical particles with a size of $0.5 \mu \mathrm{m}$.

Table 1. Aqueous leachate of the converter sludge (CS) sample.

\begin{tabular}{cccccccc}
\hline Parameter & Units & CS Original & CS & Parameter & Units & CS Original & CS \\
\hline $\mathrm{pH}$ & - & 12.0 & 8.9 & $\mathrm{Fe}$ & {$\left[\mathrm{mg} \cdot \mathrm{dm}^{-3}\right]$} & $<0.03$ & 0.17 \\
Conductivity & {$\left[\mathrm{mg} \cdot \mathrm{dm}^{-3}\right]$} & 201 & 45.0 & $\mathrm{Hg}$ & {$\left[\mathrm{mg} \cdot \mathrm{dm}^{-3}\right]$} & $<0.001$ & $<0.001$ \\
Chlorides & {$\left[\mathrm{mg} \cdot \mathrm{dm}^{-3}\right]$} & 27.2 & 57.0 & $\mathrm{Mn}$ & {$\left[\mathrm{mg} \cdot \mathrm{dm}^{-3}\right]$} & $<0.03$ & $<0.03$ \\
Nitrates & {$\left[\mathrm{mg} \cdot \mathrm{dm}^{-3}\right]$} & $<4.00$ & $<4.00$ & $\mathrm{Ni}$ & {$\left[\mathrm{mg} \cdot \mathrm{dm}^{-3}\right]$} & $<0.03$ & $<0.03$ \\
Nitrites & {$\left[\mathrm{mg} \cdot \mathrm{dm}^{-3}\right]$} & $<4.00$ & $<4.00$ & $\mathrm{~Pb}$ & {$\left[\mathrm{mg} \cdot \mathrm{dm}^{-3}\right]$} & $<0.10$ & $<0.10$ \\
Fluorides & {$\left[\mathrm{mg} \cdot \mathrm{dm}^{-3}\right]$} & 3.10 & 1.70 & $\mathrm{Se}$ & {$\left[\mathrm{mg} \cdot \mathrm{dm}^{-3}\right]$} & $<0.01$ & $<0.01$ \\
Phosphates & {$\left[\mathrm{mg} \cdot \mathrm{dm}^{-3}\right]$} & $<15.0$ & $<15.0$ & $\mathrm{Sb}$ & {$\left[\mathrm{mg} \cdot \mathrm{dm}^{-3}\right]$} & $<0.01$ & $<0.01$ \\
Sulphates & {$\left[\mathrm{mg} \cdot \mathrm{dm}^{-3}\right]$} & 51.0 & 86.0 & $\mathrm{Tl}$ & {$\left[\mathrm{mg} \cdot \mathrm{dm}^{-3}\right]$} & $<0.01$ & $<0.01$ \\
$\mathrm{Ag}$ & {$\left[\mathrm{mg} \cdot \mathrm{dm}^{-3}\right]$} & $<0.02$ & $<0.02$ & $\mathrm{~V}$ & {$\left[\mathrm{mg} \cdot \mathrm{dm}^{-3}\right]$} & $<0.03$ & $<0.03$ \\
$\mathrm{Al}$ & {$\left[\mathrm{mg} \cdot \mathrm{dm}^{-3}\right]$} & 1.48 & $<0.10$ & $\mathrm{Zn}$ & {$\left[\mathrm{mg} \cdot \mathrm{dm}^{-3}\right]$} & 0.98 & 0.06 \\
\hline
\end{tabular}


Table 1. Cont.

\begin{tabular}{cccccccc}
\hline Parameter & Units & CS Original & CS & Parameter & Units & CS Original & CS \\
\hline $\mathrm{As}$ & {$\left[\mathrm{mg} \cdot \mathrm{dm}^{-3}\right]$} & $<0.002$ & $<0.002$ & $\mathrm{Ca}$ & {$\left[\mathrm{mg} \cdot \mathrm{dm}^{-3}\right]$} & 159 & 57.0 \\
$\mathrm{~B}$ & {$\left[\mathrm{mg} \cdot \mathrm{dm}^{-3}\right]$} & 0.26 & $<0.50$ & $\mathrm{~K}$ & {$\left[\mathrm{mg} \cdot \mathrm{dm}^{-3}\right]$} & 21.2 & 19.0 \\
$\mathrm{Ba}$ & {$\left[\mathrm{mg} \cdot \mathrm{dm}^{-3}\right]$} & 0.12 & 0.08 & $\mathrm{Mg}$ & {$\left[\mathrm{mg} \cdot \mathrm{dm}^{-3}\right]$} & 2.03 & 8.50 \\
$\mathrm{Be}$ & {$\left[\mathrm{mg} \cdot \mathrm{dm}^{-3}\right]$} & $<1.00$ & $<1.00$ & $\mathrm{Mo}$ & {$\left[\mathrm{mg} \cdot \mathrm{dm}^{-3}\right]$} & - & 0.06 \\
$\mathrm{Cd}$ & {$\left[\mathrm{mg} \cdot \mathrm{dm}^{-3}\right]$} & $<0.01$ & $<0.01$ & $\mathrm{Na}$ & {$\left[\mathrm{mg} \cdot \mathrm{dm}^{-3}\right]$} & 15.2 & 13.0 \\
$\mathrm{Co}$. & {$\left[\mathrm{mg} \cdot \mathrm{dm}^{-3}\right]$} & $<0.03$ & $<0.03$ & $\mathrm{DOC} *$ & {$\left[\mathrm{mg} \cdot \mathrm{dm}^{-3}\right]$} & 7.90 & 8.20 \\
$\mathrm{Cr}$ & {$\left[\mathrm{mg} \cdot \mathrm{dm}^{-3}\right]$} & $<0.03$ & 0.08 & $\mathrm{DS} \mathrm{S}^{*}$ & {$\left[\mathrm{mg} \cdot \mathrm{dm}^{-3}\right]$} & 480 & 420 \\
$\mathrm{Cu}$ & {$\left[\mathrm{mg} \cdot \mathrm{dm}^{-3}\right]$} & $<0.03$ & $<0.03$ & & & & \\
\hline
\end{tabular}

Notes: DOC * —dissolved organic carbon, DS * — dissolved substances.

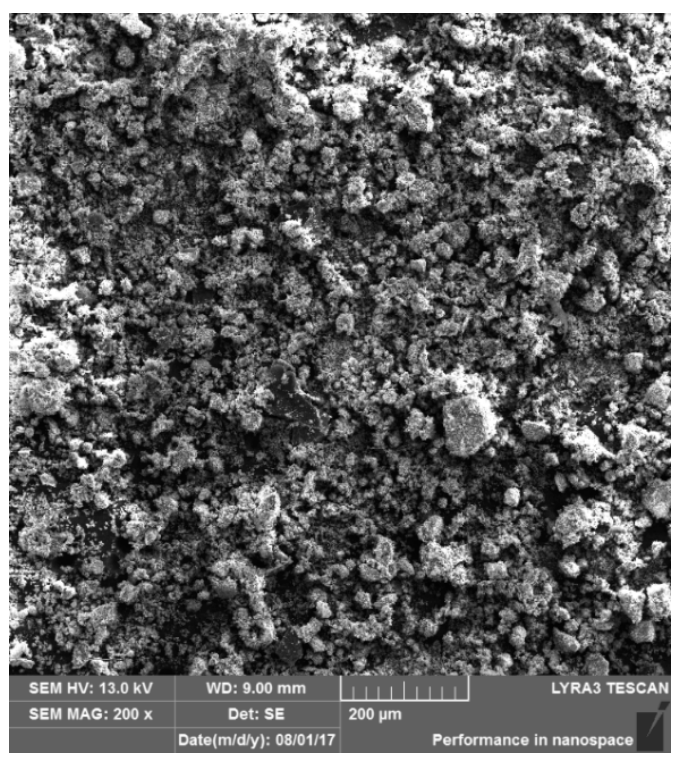

(a)

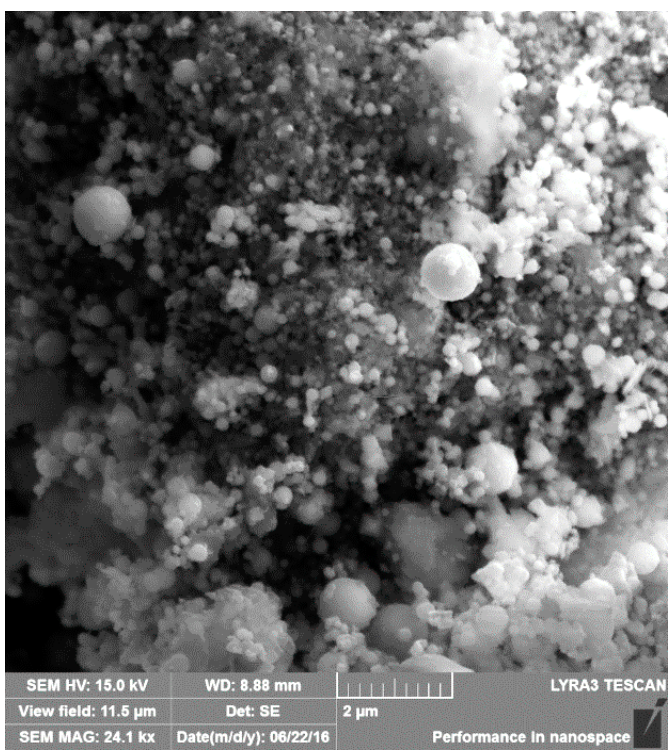

(b)

Figure 1. SEM images of original CS sample at $200 \times(\mathbf{a})$ and $24 \mathrm{k} \times(\mathbf{b})$ magnification.

Table 2. Chemical composition of the CS sample.

\begin{tabular}{cclccc}
\hline Parameter & Units & CS & Parameter & Units & CS \\
\hline $\mathrm{Ag}$ & {$\left[\mathrm{mg} \cdot \mathrm{kg}^{-1}\right]$} & 67.9 & $\mathrm{Mo}$ & {$\left[\mathrm{mg} \cdot \mathrm{kg}^{-1}\right]$} & 19.2 \\
$\mathrm{Al}$ & {$[\%]$} & 0.22 & $\mathrm{Na}$ & {$[\%]$} & 0.17 \\
$\mathrm{As}$ & {$\left[\mathrm{mg}^{-1} \mathrm{~kg}^{-1}\right]$} & $<0.40$ & $\mathrm{Ni}$ & {$\left[\mathrm{mg} \cdot \mathrm{kg}^{-1}\right]$} & 83.8 \\
$\mathrm{~B}$ & {$\left[\mathrm{mg}^{-1} \mathrm{~kg}^{-1}\right]$} & 1100 & $\mathrm{P}$ & {$[\%]$} & 0.01 \\
$\mathrm{Ba}$ & {$[\%]$} & 1.50 & $\mathrm{~Pb}$ & {$[\%]$} & 1.31 \\
$\mathrm{Be}$ & {$\left[\mathrm{mg} \cdot \mathrm{kg}^{-1}\right]$} & $<1.00$ & $\mathrm{~S}$ & {$[\%]$} & 0.09 \\
$\mathrm{Ca}$ & {$[\%]$} & 10.5 & $\mathrm{Sb}$ & {$\left[\mathrm{mg} \cdot \mathrm{kg}^{-1}\right]$} & 20.5 \\
$\mathrm{Cd}$ & {$[\%]$} & 0.06 & $\mathrm{Si}$ & {$[\%]$} & 2.27 \\
$\mathrm{Co}$ & {$\left[\mathrm{mg} \cdot \mathrm{kg}^{-1}\right]$} & 9.60 & $\mathrm{Se}$ & {$\left[\mathrm{mg} \cdot \mathrm{kg}^{-1}\right]$} & $<0.50$ \\
$\mathrm{Cr}$ total & {$[\%]$} & 6.97 & $\mathrm{Sn}$ & {$\left[\mathrm{mg} \cdot \mathrm{kg}^{-1}\right]$} & 33.6 \\
$\mathrm{Cu}$ & {$[\%]$} & 0.07 & $\mathrm{Sr}$ & {$\left[\mathrm{mg} \cdot \mathrm{kg}^{-1}\right]$} & 96.3 \\
$\mathrm{Fe}$ & {$[\%]$} & 46.8 & $\mathrm{Ti}$ & {$\left[\mathrm{mg} \cdot \mathrm{kg}^{-1}\right]$} & 178 \\
$\mathrm{Fetal}$ & {$[\%]$} & 45.1 & $\mathrm{Tl}$ & {$\left[\mathrm{mg} \cdot \mathrm{kg}^{-1}\right]$} & $<1.70$ \\
$\mathrm{FeIII} \mathrm{a} \mathrm{Fe}$ & {$[\%]$} & 1.68 & $\mathrm{~V}$ & {$\left[\mathrm{mg} \cdot \mathrm{kg}^{-1}\right]$} & 74.2 \\
$\mathrm{Hg}$ & {$\left[\mathrm{mg} \cdot \mathrm{kg}^{-1}\right]$} & 5.50 & $\mathrm{Zn}$ & {$[\%]$} & 6.53 \\
$\mathrm{~K}$ & {$[\%]$} & 0.07 & $\mathrm{Cl}$ & {$[\%]$} & 0.01 \\
$\mathrm{Mg}$ & {$[\%]$} & 0.90 & $\mathrm{~F}$ & {$[\%]$} & 0.002 \\
$\mathrm{Mn}$ & {$[\%]$} & 0.93 & Loss of ignition & {$[\%]$} & 0.77 \\
\hline
\end{tabular}


Surface texture and morphology was observed using an EDX analyzer (TESCAN, Brno, Czech Republic), and the quantitative elementary sludge composition of the sludge sample was recorded by the field analysis, which is shown in Figure 2. Figure 2 shows the largest portion of iron, calcium, and zinc, as was also evidenced by the chemical composition analysis.

Phase diffraction analysis confirmed the presence of the majority phase of iron in the analyzed CS sample (Figure 3). The CS sample is polycrystalline and contains five different crystal phases. The main phase was identified as zinc ferrite, $\left(\mathrm{Zn}_{\mathrm{x}} \mathrm{Fe}_{1-\mathrm{x}}\right) \mathrm{O}$. The other phases corresponded to $\mathrm{CaCO}_{3}$, $\mathrm{Zn}_{\mathrm{x}} \mathrm{Fe}_{3-\mathrm{x}} \mathrm{O}_{4}, \mathrm{C}$-graphite, and elemental iron $\alpha$-Fe. The resulting composition gives the assumption that the identified phases, zinc ferrite, and $\alpha$-Fe might contribute to the sorption process.

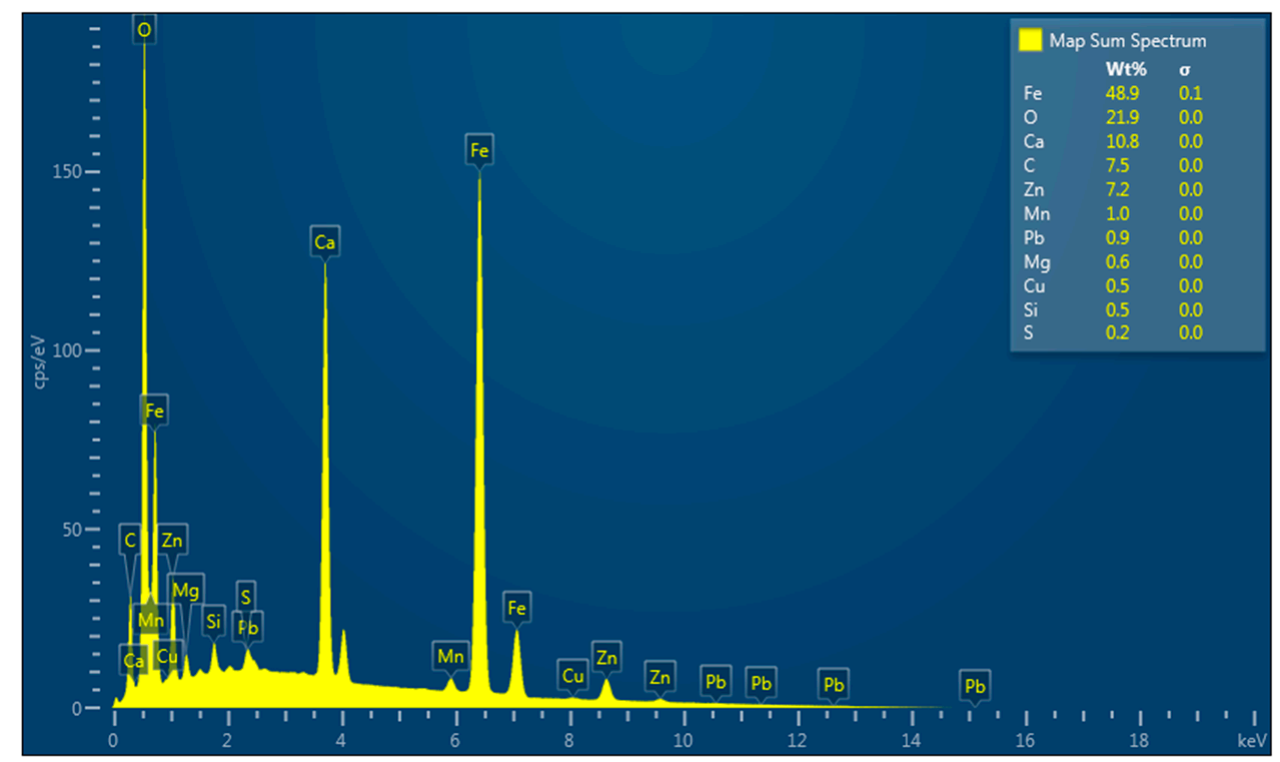

Figure 2. Quantitative elemental composition of the CS determined by EDX analysis.

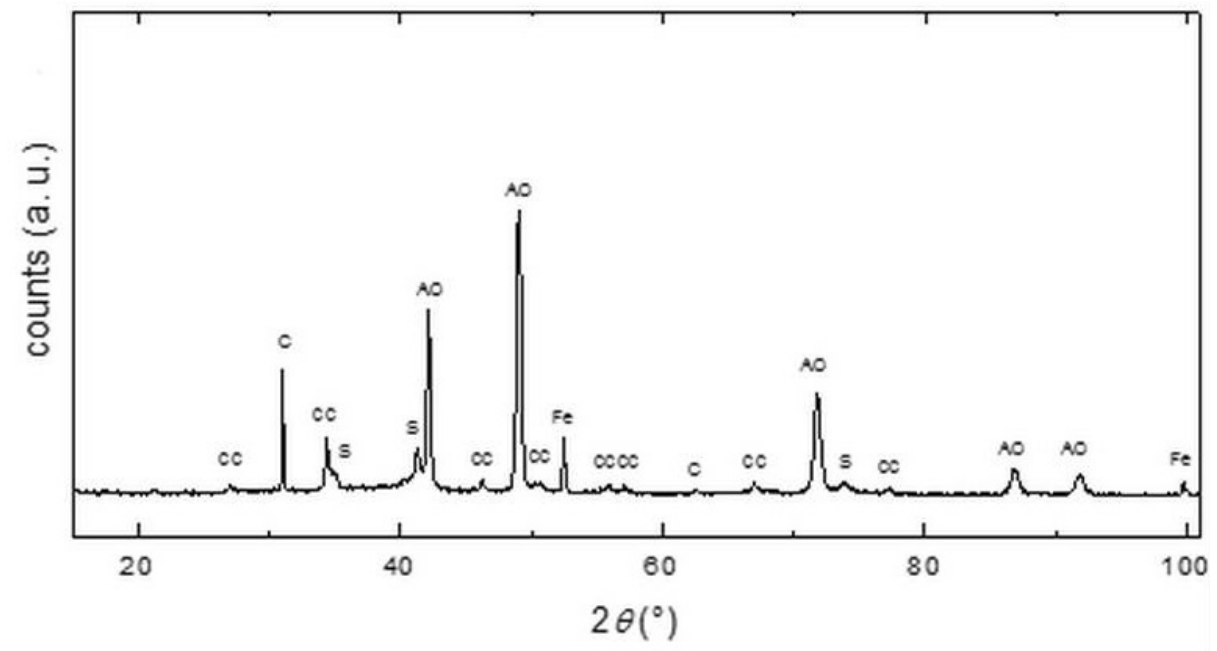

Figure 3. Diffraction record of the $\mathrm{CS}\left(\mathrm{C}-\mathrm{C} ; \mathrm{CC}-\mathrm{CaCO}_{3} ; \mathrm{AO}-\mathrm{Zn}_{\mathrm{x}} \mathrm{Fe}_{1-x} ; \mathrm{S}-\mathrm{Zn}_{\mathrm{x}} \mathrm{Fe}_{3-\mathrm{x}} \mathrm{O}_{4} ; \mathrm{Fe}-\alpha-\mathrm{Fe}\right)$.

Table 2 shows the obtained quantities from the analysis of the specific surface area using the BET method. From the measured data, it is clear that the adsorbed layer is formed with increasing pressure and the isothermal knee indicates the start of the formation of the next layer. The shape of the isotherm exhibits hysteresis, which is related to the filling of empty pores at pore pressure and pore emptying at lower pressures (Figure 4). The hysteresis loop also proves the presence of pores. 


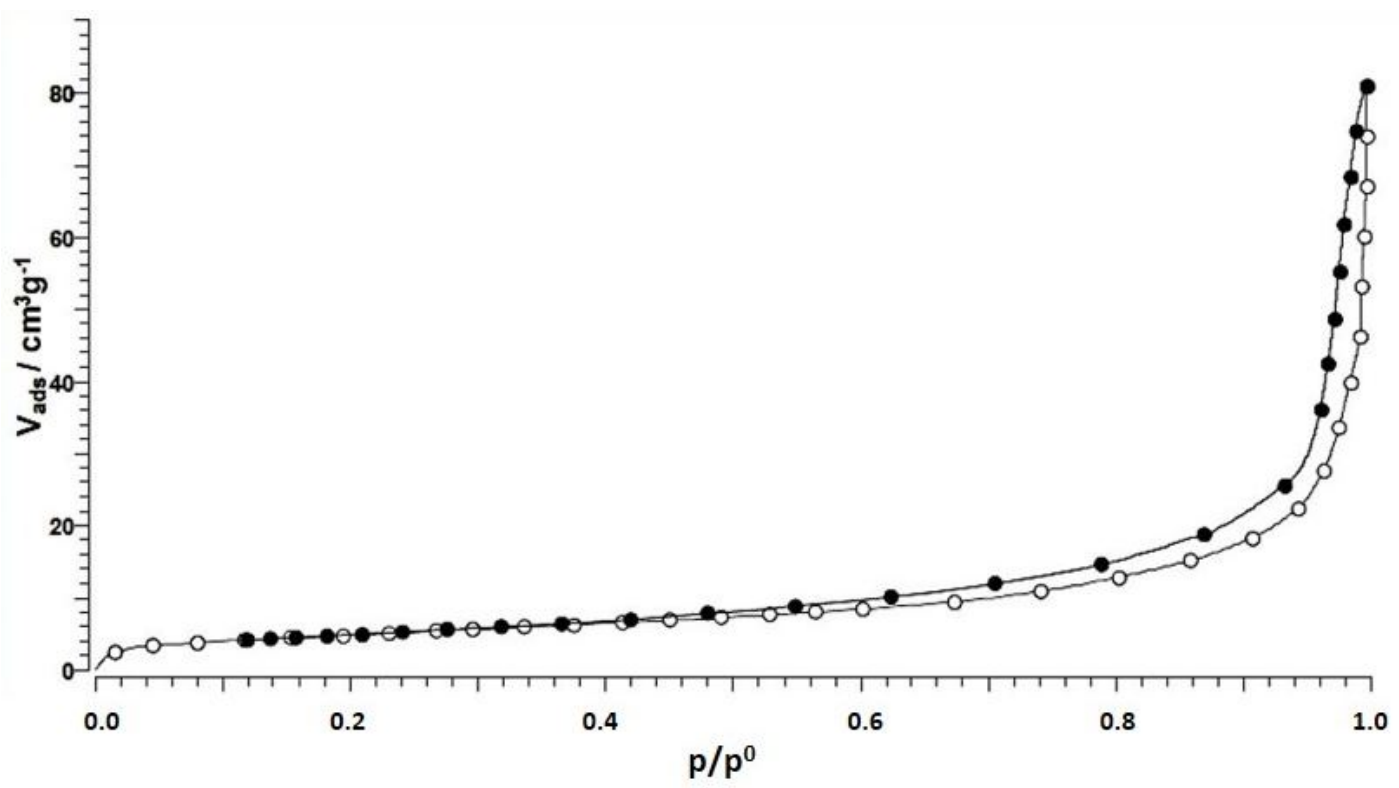

Figure 4. Isotherm of the CS sample.

It was also found from the measurement of the pore size distribution by the $\mathrm{BJH}$ method that the largest proportion of macropores and mezopores lies in the range of 50-200 nm (35\%), 10-50 nm (28\%), and $200-300 \mathrm{~nm}(20 \%)$. The remaining part of mezopores is in the range of $2-10 \mathrm{~nm}$. The surface area and pore size values are shown in Table 3.

Table 3. Results of the specific surface area and pore size of the CS.

\begin{tabular}{cccccc}
\hline \multirow{2}{*}{ Sample } & \multicolumn{2}{c}{ Surface Area } & \multicolumn{2}{c}{ Pores $(\mathrm{nm})$} & \multicolumn{2}{c}{ Micropores (nm) } \\
\cline { 2 - 6 } & {$\left[\mathrm{m}^{\mathbf{2}} \cdot \mathrm{g}^{-\mathbf{1}}\right]$} & Average & Max. & Average & Max. \\
\hline CS & 17.8 & 68.1 & 231 & 0.45 & 0.45 \\
\hline
\end{tabular}

The MW sample was used as an adsorbate or wastewater. The sample was taken from the tank quarry. The measured concentrations of the selected monitored parameters of the MW sample after the removal of undissolved substances are shown in Table 4. At the same time, the permissible limit values of the selected parameters monitored for the MW treatment plant designated by the water management authority are also given in Table 4 . The results show that the MW sample exceeds the permissible limit values for iron, manganese, and undissolved substances. Cobalt and nickel were also detected in the sample. Based on the composition of MW, the concentrations of manganese, cobalt, and nickel were monitored, in addition to the $\mathrm{pH}$ value.

Table 4. Selected parameters of mine water (MW) analysis.

\begin{tabular}{cccc}
\hline Parameter & Units & MW & Permissible Values for MW \\
\hline $\mathbf{p H}$ & - & 6.28 & $6-9$ \\
Fe $_{\text {total }}$ & {$\left[\mathrm{mg} \cdot \mathrm{dm}^{-3}\right]$} & 1.96 & 1 \\
$\mathbf{M n}$ & {$\left[\mathrm{mg} \cdot \mathrm{dm}^{-3}\right]$} & 7.06 & 0.5 \\
$\mathbf{C o .}$ & {$\left[\mathrm{mg} \cdot \mathrm{dm}^{-3}\right]$} & 0.22 & - \\
$\mathbf{N i}$ & {$\left[\mathrm{mg} \cdot \mathrm{dm}^{-3}\right]$} & 0.23 & - \\
Undissolved substances & {$\left[\mathrm{mg} \cdot \mathrm{dm}^{-3}\right]$} & 29 & 30 \\
\hline
\end{tabular}

Note: * the permissible value of the concentrations of the indicators for mine water discharged in the final effluent from the mine water treatment plant. 


\subsection{Sorption Experiment}

First experiment was conducted using CS sorbent in distilled water as a single metal ions system. The single metal ions system was carried out in distilled water for the determination of the removal efficiency, followed by the determination of monitored metal ions separately. High removal efficiency was achieved at a lower initial concentration of metal ions, as is evident from Figure 5.

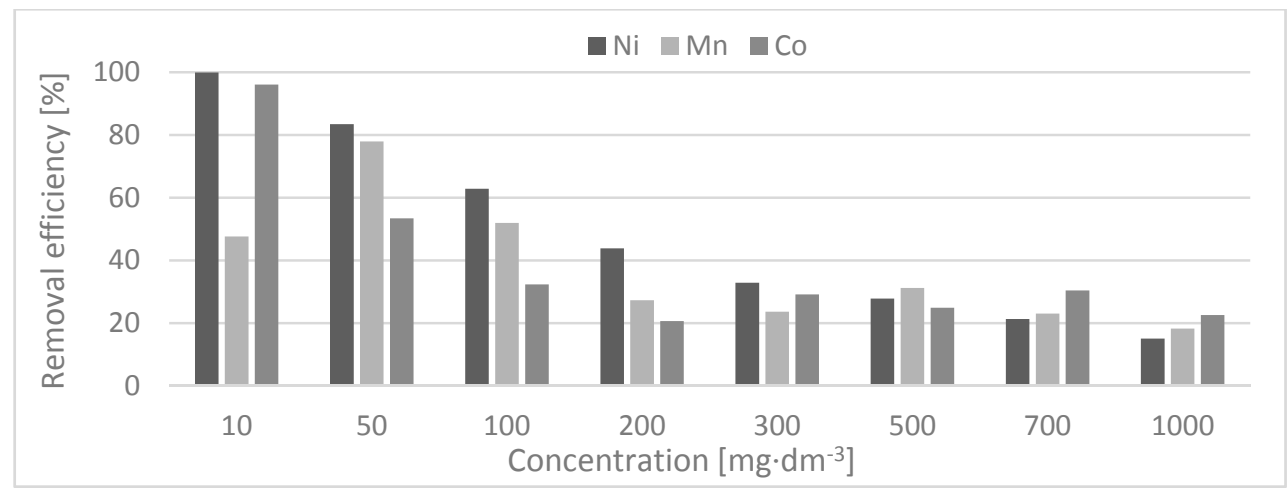

Figure 5. Dependence of removal efficiency on the concentrations of $\mathrm{Ni}(\mathrm{II}), \mathrm{Mn}(\mathrm{II})$, and Co.(II) of the CS sample. The initial concentration was $10 \mathrm{mg} \cdot \mathrm{dm}^{-3}$ and the contact time was $1 \mathrm{~h}$.

In the single metal ions system, the high correlation coefficients $\left(R^{2} \geq 0.9\right)$ obtained from Freundlich isotherm indicate that the adsorption of metal ions follows multilayer coverage on the CS sorbent surface. The parameters of Langmuir and Freundlich isotherms are listed in Table 5.

Table 5. Parameters of Langmuir and Freundlich isotherms of Ni(II), Mn(II), and Co.(II) ions for the CS sample in distilled water (single metal ions system).

\begin{tabular}{ccccc}
\hline Isotherm & Constant & Ni(II) & Mn(II) & Co.(II) \\
\hline \multirow{4}{*}{ Langmuir } & $K_{L}$ & 0.031 & 0.005 & 0.002 \\
& $q_{\max }$ & 60.98 & 90.09 & 166.7 \\
& $\mathrm{R}^{2}$ & 0.995 & 0.862 & 0.636 \\
\hline \multirow{3}{*}{ Freundlich } & $K_{F}$ & 2.889 & 0.867 & 1.049 \\
& $n$ & 4.078 & 1.395 & 1.481 \\
& $\mathrm{R}^{2}$ & 0.996 & 0.937 & 0.943 \\
\hline
\end{tabular}

The CS + MW suspension was prepared using a solid:liquid phase ratio of 1:400 for the sorption experiment with MW. The sorption experiment was carried out twice. The $\mathrm{pH}$ parameter monitoring and the dependence of the adsorption process on the reaction time were investigated as crucial factors for the successful usage of the CS waste as a sorbent. The initial $\mathrm{pH}$ value of the prepared suspension was 5.8, which stands below the limit established for MW. It is necessary to monitor the $\mathrm{pH}$ parameter due to the high content of $\mathrm{Ca}, \mathrm{Mg}, \mathrm{K}$, and Fe in the CS sample, because it could cause significant change of the $\mathrm{pH}$ value beyond permissible values for $\mathrm{MW}$, which would render the draining of the MW into the environment unacceptable. Mixing of the CS + MW suspension occurs due to the change of the $\mathrm{pH}$ value. After 24 and $48 \mathrm{~h}$, the $\mathrm{pH}$ value reached a value above 6 . After $72 \mathrm{~h}$, the $\mathrm{pH}$ value reached a value of 8.23 , which remained stable until the end of the experiment.

The effect of the removal efficiency of metal ions on the contact time was monitored at 24,48 , 72 , and $168 \mathrm{~h}$. Equilibrium was achieved after $168 \mathrm{~h}$. The $\mathrm{pH}$ value of $\mathrm{t}$ emixture was not modified. Figure 6 shows the dependence of the removal efficiency of metal ions on the contact time of the adsorbent with the adsorbate. The highest removal efficiency was achieved with a shaking time of $168 \mathrm{~h}$. Figure 6 shows the best removal efficiency of the monitored metal ions from the MW sample 
using the CS sample. The results indicate that the removal efficiency of the CS sample was $71 \%$ for $\mathrm{Mn}(\mathrm{II}), 59 \%$ for Co.(II), and $40 \%$ for $\mathrm{Ni}(\mathrm{II})$.

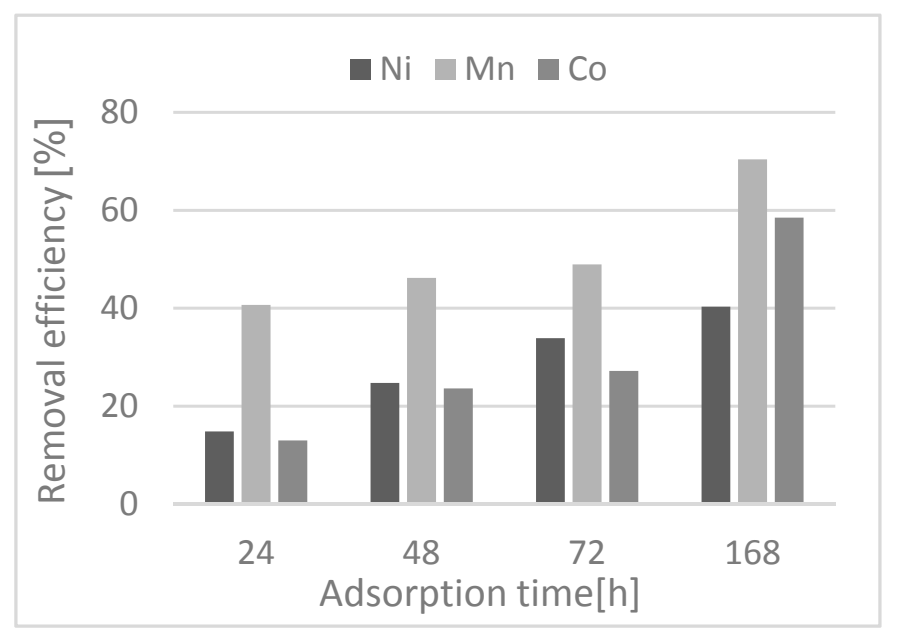

Figure 6. The dependence of the removal efficiency of $\mathrm{Ni}(\mathrm{II}), \mathrm{Mn}(\mathrm{II})$, and $\mathrm{Co}$.(II) ions on the adsorption time for the CS + MW suspension.

Kinetic parameters of the pseudo-first order and pseudo-second order kinetic models for the CS + MW suspension are shown in Table 6. Results show that the pseudo-second order model for $\mathrm{Ni}(\mathrm{II})$ and $\mathrm{Mn}$ (II) ions is preferable and has a better fit for the description of the adsorption kinetics of the CS + MW suspension. These results indicate that the bond in this process is a chemical one. For describing the adsorption kinetic from the value of the correlation coefficient for Co.(II) ions, the kinetic model cannot be uniquely determined since it only reaches a value of 0.851 .

Table 6. Kinetic parameters of the pseudo-first and pseudo-second order of the CS + MW suspension.

\begin{tabular}{|c|c|c|c|c|}
\hline \multicolumn{5}{|c|}{ Pseudo-First Order Model } \\
\hline Constant & $k_{1}$ & $q_{\text {teor }}$ & $q \exp$ & $\mathbf{R}^{2}$ \\
\hline Units & [min] & {$\left[\mathrm{mg} \cdot \mathrm{g}^{-1}\right]$} & {$\left[\mathrm{mg} \cdot \mathrm{g}^{-1}\right]$} & - \\
\hline $\mathrm{Ni}$ & 6.50 & 0.65 & 0.05 & 0.892 \\
\hline Mn & 8.00 & 72.58 & 2.45 & 0.861 \\
\hline Co. & 6.80 & 1.53 & 0.06 & 0.851 \\
\hline \multicolumn{5}{|c|}{ Pseudo-Second Order Model } \\
\hline Constant & $k_{2}$ & $q_{\text {teor }}$ & $q_{\exp }$ & $\mathbf{R}^{2}$ \\
\hline Units & [min] & {$\left[\mathrm{mg} \cdot \mathrm{g}^{-1}\right]$} & {$\left[\mathrm{mg} \cdot \mathrm{g}^{-1}\right]$} & - \\
\hline $\mathrm{Ni}$ & 18.8 & 0.06 & 0.05 & 0.988 \\
\hline Mn & 0.60 & 2.91 & 2.45 & 0.971 \\
\hline Co. & 1.50 & 0.16 & 0.06 & 0.792 \\
\hline
\end{tabular}

Figure 7 shows the measured concentration of the monitored metals in the MW sample before the sorption experiment, which is compared to the concentrations after the sorption process of the CS + MW suspension. The concentrations of the monitored metal ions decrease. The most significant change is detected for $\mathrm{Mn}(\mathrm{II})$, due to its highest concentration observed in the MW sample compared to those of Co.(II) and $\mathrm{Ni}$ (II).

The distribution coefficients of the CS + MW suspension are listed in Table 7. The results from Table 7 indicate that the sorption takes place in the CS $+\mathrm{MW}: \mathrm{Ni}$ (II) $>\mathrm{Co}$.(II) $>\mathrm{Mn}$ (II) range. 


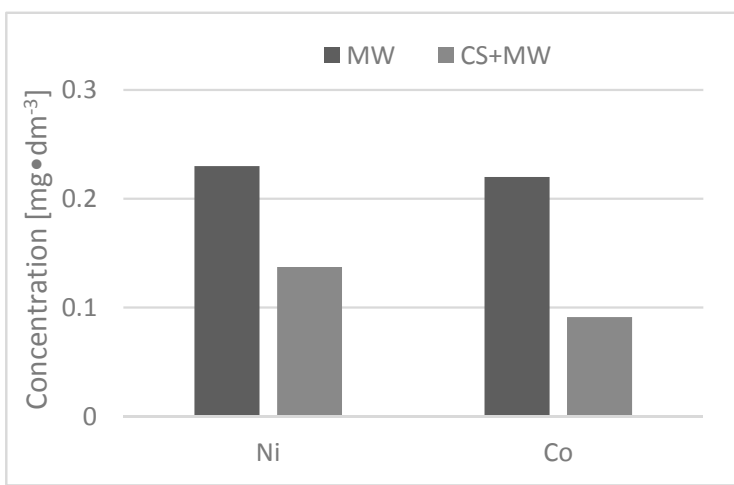

(a)

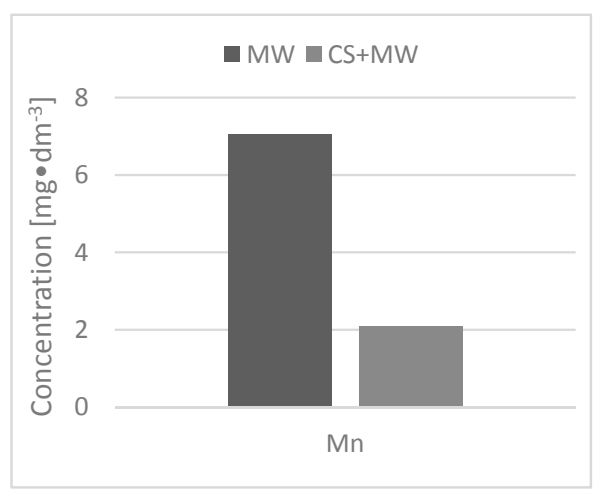

(b)

Figure 7. Comparison of the MW concentration before adsorption with the concentration of the CS + MW suspension, and after sorption of (a) $\mathrm{Ni}(\mathrm{II}), \mathrm{Co}$.(II), and (b) $\mathrm{Mn}$ (II).

Table 7. Distribution coefficients of $\mathrm{Ni}(\mathrm{II}), \mathrm{Mn}(\mathrm{II})$, and Co.(II) ions in the CS sample.

\begin{tabular}{cccc}
\hline$K_{D}\left[\mathbf{d m}^{3} \cdot \mathrm{g}^{-1}\right]$ & $\mathbf{N i}$ & $\mathbf{M n}$ & Co. \\
\hline $\mathrm{CS}+\mathrm{MW}$ & 204 & 347 & 289 \\
\hline
\end{tabular}

\subsection{Desorption Experiment}

The desorption experiment was conducted to study the interaction strength of the adsorbent with the adsorbate. This experiment was carried out after the sorption process with the suspension of CS $+\mathrm{MW}$, and the dried solid residue of CS was used for desorption. The solid residue of CS after the sorption process was shaken for $168 \mathrm{~h}$ in distilled water in the same solid to liquid ratio of 1:400 as was used during the sorption experiment. The desorption experiment was evaluated as the dependence of the leachate fraction on the distilled water. The experiment was carried out twice. The $\mathrm{pH}$ value was measured and had a value of 8.5.

Figure 8 shows the leached ratio obtained from the CS + MW suspension in the distilled water. The ratio for $\mathrm{Mn}$ (II) did not reach $0.3 \%$. Ni(II) was discharged into the distilled water with a value of about $8 \%$. The leached ratio for Co.(II) reached a value of about $33 \%$. The results show that the Mn(II) ions are the most stably bound. This can be explained by the firm bonding of $\mathrm{Mn}$ (II) ions to zinc ferrite and metallic iron.

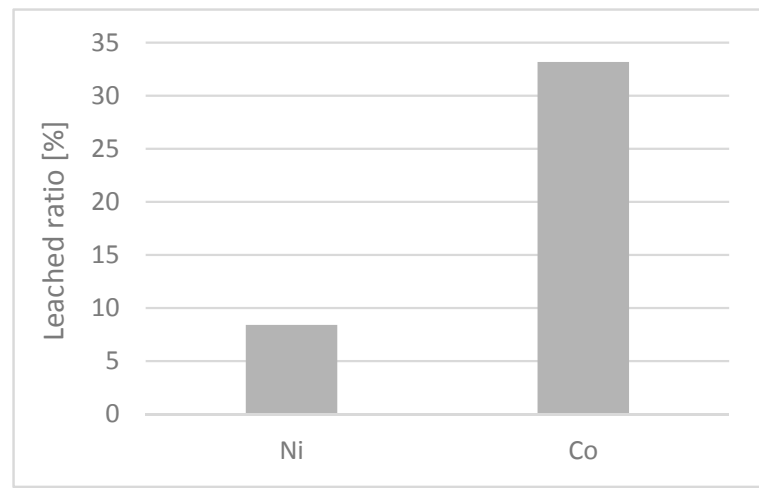

(a)

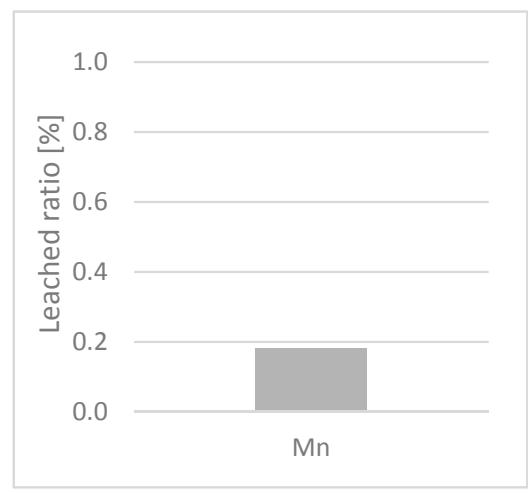

(b)

Figure 8. Leached ratio of monitored metal ions after the experiment with CS + MW suspension, (a) $\mathrm{Ni}(\mathrm{II}), \mathrm{Co} .(\mathrm{II})$, and (b) $\mathrm{Mn}(\mathrm{II})$. 


\section{Conclusions}

CS generated by the wet-gas purification process in an oxygen converter was used as a sorption material to reduce the concentrations of manganese, cobalt, and nickel ions in MW. The sorption properties of the converter sludge were verified in a real MW sample obtained from the brown coal location that was subject to the control of the $\mathrm{pH}$ value, undissolved substances, and manganese and iron concentrations before being discharged into the watercourse.

The CS includes a high content of iron (46.8\%), which is partially bound to the zinc ferrite as one of the major crystalline phases. It also contains metallic iron, a significant proportion of graphite, and calcium carbonate, which has a positive effect on the $\mathrm{pH}$ value of the MW

The predominant iron content of the CS plays an important role in the immobilization of the toxic elements. These results showed that the adsorption behaviors of $\mathrm{Mn}$ (II), Co.(II), and Ni(II) ions on the CS sorbent in a single metal ions system reach the best removal efficiency for a low initial concentration. The highest values of efficiency were reached by Ni(II), Co.(II), and Mn(II) ions, respectively. The assumption that the multi-composition of the CS creates much stronger competition on sorbent can be made based on the achieved results. Diverse binding mechanisms of heavy metal ions on different sorbents can be responsible for this effect. However, it is speculated that the "competitive effect" is not merely dependent on the total adsorption sites assigned to each fraction, but strongly depends on the surface sites that are readily "exchangeable". The CS sorbent has to show many differences as compared to the single-component system. These differences are based on the several binding mechanisms available for heavy metals on the end-member component. High efficiency of the removal of $\mathrm{Ni}$ (II) and Co.(II) ions is caused by a strong affinity to the CS sorbent. On the contrary, $\mathrm{Mn}$ (II) does not cause such a strong affinity, however, the bound with the CS is very stable, firm, and strong. Mn ions exhibit a higher bond stability against replacement by other metals compared to the metal ions adsorbed on CS. This may be due to the more stable electron configuration of Mn(II) ions compared to those of $\mathrm{Ni}$ and $\mathrm{Co}$.

The distribution coefficient indicates that the sorption takes place in the range of Ni $>$ Co. $>$ Mn. This can be explained by the size of the ionic radius. Ni(II), Co.(II), and Mn(II) occur in this range, which was confirmed by both the value of electronegativity and the distribution coefficient measurements.

The sorption process showed that the CS reduces the content of all studied metal ions and it is not necessary to modify the $\mathrm{pH}$ of the $\mathrm{MW}$ for the optimal removal efficiency. The results of the removal efficiency of metal ions from the MW reached values of $70 \%$ for $\mathrm{Mn}(\mathrm{II}), 59 \%$ for Co.(II), and $40 \%$ for $\mathrm{Ni}$ (II). The application of the kinetic models showed that the pseudo-first order model for Co.(II) and $\mathrm{Ni}(\mathrm{II})$ is more favorable for the description of this process, while for $\mathrm{Mn}(\mathrm{II})$ the pseudo-second order model is recommended.

Moreover, the high proportion of macropores and mesopores forms space for the attachment of metal ions on the surface.

The desorption study was evaluated as an interaction strength between the adsorbent and the adsorbate, and it was evaluated after the sorption experiment with the CS + MW suspension. The results showed that manganese ions are the most strongly bound, which is the monitored parameter for the discharge of the MW into the watercourse.

Summarizing all of the presented experimental results, it can be concluded that the CS sample has high potential for the removal of manganese, nickel, and cobalt ions from MW. The monitored concentrations of $\mathrm{Mn}(\mathrm{II}), \mathrm{Co}$.(II), and $\mathrm{Ni}$ (II) as well as the $\mathrm{pH}$ value in the MW after the application of the CS are below the permitted limit values for the discharge of MW into the environment. The Czech Republic produces a high amount of CS, about 26,000 tons per year. The usage of CS waste would save around $22 \%$ of annual costs for mining operations compared to the existing MW treatment methods. For practical application, the low-cost and ecological aspect of the waste material utilization offers a great advantage.

The obtained results can significantly contribute to the field of chemical metallurgy by indicating the possibility of using CS as an efficient and prospective sorbent. 
Acknowledgments: The authors are grateful for the financial support from the Ministry of Education, Youth and Sports of the Czech Republic; Project LQ1603 (Research for SUSEN). This work has been realized within the SUSEN Project (established in the framework of the European Regional Development Fund (ERDF)) in project CZ.1.05/2.1.00/03.0108 and project TA CR-Gama TG02010037.

Author Contributions: Lucia Rozumová conceived, designed and performed the experiments; Lucia Rozumová performed SEM analyses; Jana Prehradná contributed analysis tools; Lucia Rozumová and Jana Prehradná wrote the paper.

Conflicts of Interest: The authors declare no conflict of interest.

\section{References}

1. Český Statistický úřad. Produkce, Využití a Odstranění, Odpadi̊. Available online: https://www.czso.cz/ csu/czso/produkce-vyuziti-a-odstraneni-odpadu-2014 (accessed on 6 August 2017).

2. Ahmaruzzaman, M. Industrial wastes as low-cost potential adsorbents for the treatment of wastewater laden with heavy metal. Adv. Colloid Interface Sci. 2011, 166, 36-59. [CrossRef] [PubMed]

3. Trung, Z.H.; Kukurugya, F.; Takacova, Z.; Orac, D.; Laubertova, M.; Miskufova, T.; Havlik, T.J. Acidic leaching both of zinc and iron from basic oxygen furnace sludge. Hazard. Mater. 2011, 192, 1100-1107. [CrossRef] [PubMed]

4. López-Delgado, S.V. Sorption of heavy metals on blast furnace sludge. Water Res. 1998, 32, 989-996. [CrossRef]

5. López, F.A. Removal of copper ions from aqueous solutions by a steelmaking by-product. Water Res. 2003, 37, 3883-3890. [CrossRef]

6. Rozumová, L. Magnetically modified peanut husks as an effective sorbent of heavy metals. J. Environ. Chem. Eng. 2016, 4, 549-555. [CrossRef]

7. Lottermoser, B. Mine Wastes: Characterization, Treatment and Environmental Impacts; Springer: New York, NY, USA, 2012; ISBN 978-3-662-05133-7.

8. Moreno, N.; Querol, X.; Ayora, C. Utilization of zeolites synthesised from coal fly ash for the purification of acid mine waters. Environ. Sci. Technol. 2001, 35, 3526-3534. [CrossRef] [PubMed]

9. Manchisi, J.; Rowson, N.A.; Simmons, M.J.H. Kinetics of Metals Adsorption in Acid Mine Drainage Treatment with Blast Furnace Slag; School of Chemical Engineering, University of Birmingham: Birmingham, UK, 2013.

10. Feng, D.; Deventer, J.S.J.; Aldrich, C. Removal of pollutants from acid mine wastewater using metallurgical by-product slags. Sep. Purif. Technol. 2004, 40, 61-67. [CrossRef]

11. Prasad, B.; Mortimer, R.J.G. Treatment of acid mine drainage using fly ash zeolite. Water Air Soil Pollut. 2011, 218, 667-679. [CrossRef]

12. Ivanets, A.I.; Kitikova, N.V.; Shashkova, I.L.; Oleksiienko, O.V.; Levchuk, I.; Sillanpää, M. Using of phosphatized dolomite for treatment of real mine water from metal ions. J. Water Process Eng. 2016, 9, 246-253. [CrossRef]

13. Council Directive 1999/31/EC on the Landfill of Waste. 1999. Available online: http: / / eur-lex.europa.eu/ legal-content/EN/TXT/?uri=celex\%3A31999L0031 (accessed on 8 September 2017).

14. Corbitt, R.A. Standard Hand Book of Environmental Engineering, 2nd ed.; The McGraw-Hill Companies, Inc.: Columbus, OH, USA, 1999; ISBN 9780070131606.

15. Amuda, O.S. Performance optimization of coagulant/flocculant in the treatment of wastewater from a beverage industry. J. Hazard. Mater. B 2006, 129, 69-72. [CrossRef] [PubMed]

16. Leiviska, T.; Khalid, M.K.; Sarpola, A.; Tanskanen, J. Removal of vanadium from industrial wastewater using iron sorbents in batch and continuous flow pilot systems. J. Environ. Manag. 2017, 190, 231-242. [CrossRef] [PubMed]

17. EN 12457-4:2002 Characterisation of Waste-Leaching-Compliance Test for Leaching of Granular Waste Materials and Sludges-Part 4: One Stage Batch Test at a Liquid to Solid Ratio of 10 1/kg for Materials with Particle Size below $10 \mathrm{~mm}$ (without or with Size Reduction). 2002. Available online: http:/ / csnonlinefirmy. unmz.cz/html_nahledy/83/67132/67132_nahled.htm (accessed on 11 September 2017).

18. Council Decision 2000/532/EC Establishing Criteria and Procedures for the Acceptance of Waste at Landfills Pursuant. 2003. Available online: http:/ / eur-lex.europa.eu/legal-content/en/ALL/?uri=CELEX\% 3A32000D0532 (accessed on 9 September 2017). 
19. Xie, J.; Lin, J.; Zhou, X.; Zhou, G. Plutonium partitioning in three-phase systems with water, colloidal particles, and granites: New insights into distribution coefficients. Chemosphere 2014, 99, 125-133. [CrossRef] [PubMed]

20. Ajaelu Chijioke, J.; Oluwafunke, L.; Adedeji, V.; Olafisoye, O. Equilibrium and Kinetic Studies of the Biosorption of Heavy Metal (Cadmium) on Cassia siamea Bark. Am.-Eurasian J. Sci. Res. 2011, 6, 123-130.

21. Plazinski, W.; Rudzinski, W.; Plazinska, A. Theoretical models of sorption kinetics including a surface reaction mechanism: A review. Adv. Colloid Interface Sci. 2009, 152, 2-13. [CrossRef] [PubMed]

22. Mack, C.L.; Wilhelmi, B.; Duncan, J.R.; Burgess, J.E. Recovery of platinum ions from aqueous solution by immobilized Saccharomyces cerevisiae biomass: A kinetic analysis. Miner. Eng. 2008, 21, 31-37. [CrossRef]

23. Plazinski, W.; Dziuba, J.; Rudzinski, W. Modeling of sorption kinetics: The pseudo-second order equation and the sorbate intraparticle diffusivity. Adsorption 2013, 19, 1055-1064. [CrossRef]

(C) 2018 by the authors. Licensee MDPI, Basel, Switzerland. This article is an open access article distributed under the terms and conditions of the Creative Commons Attribution (CC BY) license (http://creativecommons.org/licenses/by/4.0/). 